\title{
Behavioral and Social Influences on Food Choice
}

\author{
Marion Nestle, PhD, MPH, New York University, New York NY (Co-chair); Rena Wing, PhD, University \\ of Pittsburgh, Pittsburgh PA (Co-chair); Leann Birch, PhD, Penn State University, University Park PA; \\ Lorelei DiSogra, $\mathrm{PhD}$, Dole Foods, San Mateo CA; Adam Drewnowski, PhD, University of Michigan, \\ Ann Arbor MI; Suzette Middleton, PhD, Procter \& Gamble, Cincinnati OH; Madeleine Sigman-Grant, \\ $\mathrm{PhD}$, University of Nevada, Cooperative Extension, Las Vegas NV; Jeffery Sobal, PhD, Cornell \\ University, Ithaca NY; Mary Winston, $\mathrm{PhD}$, American Heart Association, Dallas TX; Christina Economos, \\ $\mathrm{PhD}$, Tufts University, Medford MA*
}

\section{Introduction}

A blend of many factors, ranging from biological to anthropologic, interact in complex and changing ways to influence the development and maintenance of food choices. Understanding behavioral influences within the context of psychosocial influences is critical to the development of dietary recommendations, nutrition programs, and educational messages that will assist consumers in constructing healthful diets and promote dietary change. To select the most appropriate targets of change (i.e., the most critical beliefs and behaviors), it is important to know and understand the critical influences on food choice and ascertain which of these are subject to modification.

Historically, the public health approach to dietary change has been based on the premise that consumers will abandon those dietary behaviors that are demonstrably unhealthy in order to prevent future illness. Although the assumption that knowledge shapes behavior may appear self-evident, evidence suggests that providing information about risk does not have much effect on food behavior unless it can overcome counteracting psychosocial, behavioral, and environmental barriers. ${ }^{1}$ If dietary change were simple, then dissemination of information would automatically lead to behavior change. However, this has not occurred for any dietary behavior.

Eating behaviors are acquired over a lifetime; to change them requires alterations in habits that must be continued permanently-long beyond any short-term period of intervention. Dietary guidelines aimed at reducing fat consumption often advocate avoiding specific foods or even categories of foods and can be perceived as overly restrictive. Monotonous diets have the added disadvantage of being unpalatable and may be regarded as unsat- isfying and unpleasant. Furthermore, they may not be compatible with cultural or familial standards of appropriate food intake. Dietary changes may require increased cost, knowledge, skill, time, or effort needed for food preparation. ${ }^{2}$ Environmental factors such as peer pressure, advertising, and other cultural determinants may strongly oppose recommended changes. ${ }^{1}$ Social and political values and economic considerations, such as access, may also constitute obstacles to dietary change. Together, these barriers suggest that dietary advice is far easier to give than to accept and adopt.

To illustrate the difficulty encountered when initiating dietary change, consider the following example. A 50year-old woman learns that her traditional food choice of $2 \%$ milk isn't as low in fat as she thought, so she decides to change to skim milk. Most would describe this as a simple behavior change, but it is in fact rather complex. First, she needs to locate a store that carries skim milk. If her market doesn't carry it, she either must change markets or request that this product be made available. If other family members prefer other types of milk, she will need to consider storage space for several kinds of milk, money to purchase several kinds of milk, whether she should use the skim milk in making family meals, and how she might get skim milk at work. The point here is that numerous decisions accompany a seemingly simple, singular dietary behavior change. Moreover, before, during, and even after the commitment to change, positive benefits must continually outweigh any barriers to making and maintaining that change. The greater the number of factors affecting change, the greater the potential number of barriers and the more difficult it is to make and sustain dietary change.

Another case in point is the example of dietary fat.

*Reprint requests to Christina Economos, PhD, Tufts University, 132 Curtis Street, Medford MA 02155. 
Despite more than two decades of recommendations for fat reduction and the introduction of nearly 6000 new fatmodified foods within the last 5 years, ${ }^{3}$ the population as a whole does not appear to be reducing its absolute intake of dietary fat. Although the reported percent of calories from fat in the United States declined from 36-37\% in 1965 to $34 \%$ in 1991 , reported energy intake has increased from 1989 to 2153 calories per day, so absolute reported grams of fat are about the same. ${ }^{4}$ In addition, two-thirds of U.S. adults are rather inactive. ${ }^{5}$ Together these trends help explain the large recent increase in the prevalence of obesity. ${ }^{4,6}$

This working report first examines behavioral and social influences on food choice and then reviews existing research as to how social, environmental, behavioral, and individual influences affect compliance with dietary change, especially changes in dietary fat. Finally, it identifies gaps in knowledge and outlines recommendations for research.

\section{Behavioral and Social Influences on Food Choice and Eating Behavior}

Most work on food choices has focused on physiologic and psychologic determinants, with less attention given to the cultural, historical, social, and demographic considerations. Disparate data exist in studies of the determinants of food choice, much of which still require integration and synthesis across various levels of analysis. Future thinking on this topic needs to deal with the distinctions between biological versus social, organism versus population, and micro versus macro levels of analysis. It is also important to examine how healthy food choice behaviors are associated with other health promotion behaviors such as not smoking, being physically active, and wearing seat belts. ${ }^{7}$

\section{Societal-Level Influences}

Cultural values. Culture is the pervasive foundation that underlies all food choices. People use the categories and rules of their specific cultures, subcultures, and ethnic groups to frame what they consider to be acceptable and preferable foods, the amount and combination of foods they choose, and the foods they consider ideal or improper.

As people in more traditional societies enter the food system and adopt the foodways of more affluent Western societies, they enter a "nutrition transition," typically becoming acculturated into preferring and consuming a diet higher in fat. The chief characteristic of this transition is a dietary shift away from coarse grains and starchy roots toward more energy-dense fats, saturated fats, and sugars. ${ }^{8-10}$ That trend may be driven by a taste-mediated desire for a more varied and energy-dense diet. ${ }^{11}$ As meat, milk, dairy products, and fresh vegetables and fruit are incorporated into the diet, the proportion of dietary sugar and fat increases as well. The nutrition transition is also associated with increased urbanization and greater availability of processed foods, some of which are high in fat, sugar, and salt., 9,10,12

Perceptions, beliefs, attitudes, and values. People construct their perceptions, beliefs, and attitudes about foods on the basis of cultural values, with psychosocial factors shaping their food choices. Such wider cultural constructions may not be congruent with scientific constructions regarding the safety or nutrition values of foods. For example, public perceptions of the risk of irradiated foods differ from those of food scientists and nutritionists, as the public tends to amplify the undesirability of imposed, uncertain, technological, and uncontrollable risks, and to be less concerned about risks over which they have choices. ${ }^{13}$

On a societal level, food and nutrition are rarely very high on the public agenda of social problems except when the problems are dramatic, acute, and have significant consequences. ${ }^{14}$ The construction of specific dietary issues into social problems does not necessarily conform to scientific models that weigh prevalence and severity, as it may also be influenced by the actions of social groups with vested interests in promoting or suppressing par ticular problems on the public agenda. ${ }^{14,15}$ In recent decades, the promotion of high levels of fat consumption as a social problem has been fairly successful, even to the point of inducing a "fat phobia" in certain segments of society. Health, consumer, and food industry groups have had much to gain and lose as perceptions, beliefs, attitudes, and values about fat have shifted. Consequently, these groups have actively campaigned to encourage or suppress the level and direction of concern about fat. These societal dynamics affect views of the role of dietary fat in contemporary society. ${ }^{16}$

Social influences. Most eating occurs in the presence of others. Research clearly indicates that a social facilitation effect leads to lower levels of food consumption when people eat alone and to higher levels when eating occurs in a group setting, especially when the groups are composed of familiar people. ${ }^{17}$ Family and friends provide a source of modeling and peer pressure for consuming particular foods, including higher-fat foods, and for trying new foods. ${ }^{14}$ Family involvement is important in making and sustaining dietary change, as shown in studies on cardiovascular disease risk reduction and in the treatment of obesity and eating disorders. ${ }^{18-20}$ Conversely, lack of social support can sabotage dietary change. ${ }^{21}$

The media and advertising. The media are a principal source of information about food and nutrition for many 
people..$^{22}$ In addition, the media have the capacity to persuade. Research documenting coverage of an issue and consumer response (i.e., decreased consumption or increased sales) has demonstrated the powerful influence of the media in our society. ${ }^{23-26}$

The U.S. food system is the economy's largest advertiser. ${ }^{27}$ Successful campaigns target specific groups, reach a broad audience, and repeat messages frequently. ${ }^{28}$ The cost of advertising accounts for 3.5 cents out of every dollar the public spends on food, ${ }^{29}$ and food companies spent more than $\$ 30$ billion to advertise their products in $1994 .^{30}$ The most money is spent on advertising by companies that produce sweet, high-fat products that are more highly processed and packaged. ${ }^{31}$ Because sales and marketing figures for advertised food products often constitute proprietary information, it is difficult to establish a direct relationship between advertising and sales. Nevertheless, considerable evidence supports the effectiveness of advertising in increasing purchases of food products. ${ }^{32}$ For example, federally sponsored generic promotion programs have demonstrated a direct, positive relationship between advertising expenditures and sales for a wide range of commodities such as milk, cheese, grapefruit juice, and orange juice. ${ }^{33}$ Furthermore, advertising has been shown to influence consumer beliefs, experimentation with new products, and brand switching. ${ }^{32}$

Food advertising directed toward children is of particular concern. The effectiveness of marketing campaigns targeted to younger age groups is well known to advertisers of tobacco ${ }^{34}$ and beer. ${ }^{35}$ Food advertising has long been known to increase children's knowledge of brand names, to foster more positive attitudes toward consumption of heavily advertised snack foods, to shift beliefs about advertised foods, to encourage demands that caretakers purchase advertised foods, and to stimulate direct sales of advertised foods to children with discretionary spending money. ${ }^{36,37}$

Advertisements that employ health claims increase sales. When Kellogg's cereal packages included statements about the cancer-preventing benefits of high-fiber diets, consumer purchases of its high-fiber cereals increased by $47 \%$ within the first 24 weeks of the campaign. ${ }^{24}$ More recently, marketing efforts of the California Five-ADay campaign have been associated with increases in consumption of fruits and vegetables in that state, at least among better-educated and higher-income consumers. ${ }^{26}$ The use of marketing techniques to encourage purchases of food products labeled as "healthier," however, raises issues related to the appropriateness of such methods. ${ }^{38}$ Health claims for one attribute of a particular product (e.g., low-fat) also raise issues because foods may be healthier for one reason, but rather unhealthy for other reasons (e.g., high in calories or salt).

Numerous studies have addressed the question of whether threats or arousal of fear in messages will stimulate people to make desired dietary changes. On balance, these studies conclude that both positive and negative messages are influential in shaping short-term changes in nutrition knowledge and attitudes, but that no nutrition message is particularly effective in inducing a permanent change in behavior. ${ }^{39,40}$

Availability. For the most part, the foods that people desire are readily available to them. Because of the rapid response by the food industry, foods that people like and consume are readily made available in an ever-widening array of choices. More than 30,000 different items are available in U.S. supermarkets, ${ }^{41}$ and the typical shopper averages 2.2 visits to the supermarket each week. ${ }^{42}$ However, availability can mean different things to different groups of people. "Overall" availability may be described as the array of food options that are present and accessible in the food system, acceptable to the consumer, and affordable, whereas "immediate" availability may refer to the readiness and convenience of a food-whether it can be stored for a long time without spoilage, requires little or no cooking or preparation time, can be eaten anywhere, and is packaged as an individual serving. ${ }^{43}$

The availability of foods within a community (at restaurants, businesses, schools, grocery stores, community centers, and worksites) is dependent upon a number of interrelated factors such as budget, potential profit margin, adequate storage and refrigeration, and consumer demand. Featured products tend to be those that sell the fastest. Consequently, foods may be relatively unavailable, or available as a small percentage of total volume, or only available at a higher cost. ${ }^{44}$

At 3.8 meals per week on average, Americans are eating an increasing number of meals outside the home, ${ }^{45}$ with per capita expenditures on food away from home at $38 \%$ of total food costs. ${ }^{46}$ The American lifestyle has increased the demand for more ready-to-eat, economical alternatives, which are often packaged, processed, and preportioned foods, typically high in fat and sodium. Thus, limited availability of healthful ready-to-eat foods may narrow good choices and discourage people from consuming a healthful diet.

Although increased income does not necessarily lead to improvements in dietary quality, cost clearly influences food choices. ${ }^{4-47}$ For example, costly foods such as fish, lean meats, and fresh fruits and vegetables are less likely to be available in poor urban and rural communities. Even when such foods are available, inadequate funds may limit purchase and consumption. Improving the availability of healthier foods may be one of the most powerful approaches to influencing food selection.

Variety. Varied diets are associated with higher levels of nutrient intake ${ }^{48-50}$ and reduced risk of mortality. ${ }^{51}$ People who consume a greater variety of foods eat more food..$^{48,52}$ 
Variety, however, is sometimes, ${ }^{49}$ but not always, ${ }^{53}$ associated with increases in intake of energy, fat, sugar, sodium, or cholesterol. Increasing variety in the narrower sense of increasing fruit and vegetable consumption may or may not reduce the consumption of high-fat foods. Eating a variety of fruits and vegetables, for example, does not lead to reduced fat intake unless intake of higher-fat meat, dairy, and processed foods is also reduced. ${ }^{54}$

\section{Individual-Level Influences on Eating Behavior}

Food preferences. Most consumers state that their food choices are largely determined by taste, as opposed to any consideration of nutrition or food safety. ${ }^{41}$ The consumer concept of food "taste" also includes smell and the oral perception of food texture. ${ }^{55-57}$ Sensory responses to taste, smell, sight, and texture of foods are a major influence on both food preferences and eating habits. Energydense foods are highly preferred across all geographical, ethnic, and cultural boundaries, an observation that suggests that adult human preference for fat, sugar, and salt may be under physiologic control.

Research on preferences for high-fat foods in humans and rats has run the gamut from molecular biology to behavior to macroeconomics. Elevated fat consumption has been variously associated with genetic mutations (leptin); ${ }^{58,59}$ altered brain levels of galanin, neuropeptide $Y^{60}$ or endogenous opiate peptides; ${ }^{61}$ higher body mass ${ }^{62,63}$ or body fat; ${ }^{64}$ body mass of parents; ${ }^{65}$ learned preferences for energy-dense foods; ${ }^{66}$ high energy density of fat-rich foods; ${ }^{67}$ failure of the satiety system; ${ }^{68}$ weight cycling (in rats $)^{69}$ and the binge eating disorder (in humans) $;^{70}$ as well as urbanization, ${ }^{8,71}$ disposable income, and rising gross national product.9,12,72

Despite recent claims for the evidence of a fat "receptor," $" 73$ the current scientific consensus is that oral perception of fat content is largely guided by sensations of smell and texture. "The sensory response to fat first involves perception through the nose or mouth of fat-soluble volatile flavor molecules that impart characteristic flavors or aromas. Subsequent oral perception of fat is determined by food texture during chewing or swallowing. Oral sensation of fats depends on the type of food-meat or dairy, liquid or solid, raw or cooked. For example, fat in dairy products takes the form of emulsified globules that are perceived as smooth and creamy. ${ }^{74,75}$ The water-binding qualities of fat account for the tenderness and juiciness of steaks and the moistness of cakes and baked goods. Heat transfer at high temperature gives rise to textures that are crispy, crunchy, and brittle. Textural qualities that depend on the fat content of foods include hard, soft, juicy, chewy, greasy, viscous, smooth, creamy, crunchy, and crisp. ${ }^{76}$ Generally, diets containing fat are more varied, appealing, aromatic, and rich, and provide higher energy density.

Preferences for sweet taste are both innate and uni- versal. Human neonates show a positive hedonic response to sweet solutions. ${ }^{77}$ Young children's food preferences (ages 3-5 years) are determined in large part by sweetness and familiarity. ${ }^{78}$ Young children also like intensely sweet sugar solutions up to concentrations as high as $20 \%$ sucrose wt/vol. ${ }^{79}$ Sensory preferences for sweetness decline with age, more markedly for girls than for boys. ${ }^{80}$

Children's preferences for high-fat foods and foods high in both fat and sugar are shaped through their experience. Taste preferences for fats are acquired either in infancy or early childhood. ${ }^{81}$ An innate preference seems unlikely because fat imparts different characteristic textures to different foods; fat makes ice cream creamy, hamburgers greasy, and pastries flaky. Fat also acts as a flavor carrier for fat-soluble flavor molecules. Fats that are liquid at the temperature of the oral cavity release such molecules very efficiently (i.e., flavored olive oil).

Flavor responses have a direct impact on food consumption in children, since children typically eat more of the foods they like best ${ }^{82}$ and reject foods they dislike in either taste or texture. In contrast, links between taste preferences and food consumption in adults are much less direct. Adults do not necessarily equate palatability with sweet taste, and their taste preferences or dislikes do not necessarily relate to patterns of food consumption. Concerns with health, body weight, and appearance can lead to dietary restriction, avoidance of sugars and fats, and the consumption of "healthy" but otherwise unappealing foods. The dissonance between cognitive and sensory factors in adults has been the topic of numerous studies on aging, obesity, and eating disorders. ${ }^{63,64,69,83,84}$

Food preferences may differ by gender. ${ }^{85}$ While obese men preferred meat dishes and other combinations of fat and protein, obese women overwhelmingly selected sweet desserts, chocolate, ice cream, and other mixtures of fat and sugar. A similar pattern has been observed with normal weight men and women, such that preferences for sugar and fat, and in some cases fat and salt, are a characteristic female trait.

Learning history. Although learning about food and eating continues throughout the life span, much occurs during the first 5 years of life. These years involve a transition from an exclusive milk diet high in fat (50\% of energy from milk fat), to a lower-fat diet. ${ }^{86}$ In contrast, current recommendations suggest that children consume $30 \%$ of energy from fat by the end of the preschool period. The transition involves learning to accept a variety of solid and liquid foods.

Early learning about food and eating is constrained by children's genetic predispositions ${ }^{87}$ and by their prior experience with milk. ${ }^{88}$ These predispositions include rejection of sour and bitter tastes. ${ }^{77}$ Parents interpret infants' gustofacial responses to the basic tastes as reflecting likes and dislikes, and use these as a guide to select- 
ing foods for the infant. Young children are predisposed to reject new foods (neophobic), although this response can be altered with repeated opportunities to eat the new foods. The quantity and quality of early food experience provide the substrate for learning about food and are critical in shaping children's food preferences and food selection. Repeated opportunities to eat a new food can convert an initially rejected new food to an accepted or a preferred food. ${ }^{89}$

An analysis of the ways in which high-fat foods are presented to children, especially the social contexts and the postingestive consequences of eating, reveals many opportunities to shape preferences for these foods. For example, high-fat foods may become preferred when fed in positive contexts, used as rewards, served as an integral part of celebrations and holidays, or paired with other preferred tastes. ${ }^{90} \mathrm{High}$-fat foods are also likely to be preferred by other family members who serve as models for the young child. ${ }^{81,90}$ Foods high in energy density and fat also produce positive feelings of satiety that can serve as unconditioned stimuli for learned preferences. In situations where foods high in sugar, fat, and salt serve as rewards, the functions of food can become confused. Thus, parents inadvertently can teach children to like the very foods that nutrition guidelines advise be eaten in limited quantities (e.g., foods high in fat and sugar).

Aversions and dislikes are also formed early in life. Even a single pairing of a taste with nausea and vomiting can result in an aversion; $; 1$ preferential responses to sweet and salty flavors in foods also can be altered through experience. ${ }^{92}$ In addition, foods eaten in order to obtain rewards can often become disliked. ${ }^{78}$

Learned preferences for energy-dense foods were first demonstrated in laboratory rats, ${ }^{93}$ and more recently in young children. ${ }^{78}$ When children have repeated opportunities to consume either an energy-dense, high-fat food or an energy-dilute, fat-free version of the same food, they learn to prefer the high-energy-density food over energydilute versions of the same food. These preferences are especially pronounced when hungry. In summary, children do not have to learn to like sweet and salty foods. For foods in which other flavors predominate, preferences depend upon the context and consequences of ingestion; children choose what they like from among foods offered. ${ }^{82}$

Energy density also affects how much food children consume. Evidence suggests that infants ${ }^{94}$ and young children ${ }^{78}$ can adjust their volume of intake in response to alterations in the energy density of the diet. Although the intake of young children's individual meals is erratic, 24hour energy intake is relatively well regulated ${ }^{78}$ Individual differences in self-regulation of energy intake are associated with differences in child feeding practices, and with the adiposity of children and parents. ${ }^{82,89}$ Moreover, offer- ing a diet that is moderate in fat content does not insure its consumption..$^{95,96}$ Thus, child feeding practices have the potential to affect energy balance by altering patterns of food preferences, food selections, and the amounts consumed.

The imposition of stringent parental controls can potentiate preferences for high-fat, energy-dense foods; limit children's acceptance of a variety of foods; and disrupt children's regulation of energy intake by altering children's responsiveness to internal cues of hunger and satiety. Such reactions can occur when parents assume that children need help in determining what, when, and how much to eat, and impose feeding practices that provide children with few opportunities for self-control. ${ }^{80}$

An understanding of the factors influencing children's food preferences, including their preferences for high-fat foods, can help explain how adults acquire eating patterns inconsistent with dietary recommendations, and may suggest opportunities for preventive interventions that can shape more healthful diets. Recent evidence reveals that only $1 \%$ of U.S. children eat diets that meet current dietary guidelines; ${ }^{97}$ as much as $45 \%$ of children's daily energy intakes are derived from discretionary sugar and fat. ${ }^{98}$

Knowledge. People may use knowledge of the lipks between diet and health to change their behavior, but knowledge alone is unlikely to be effective. ${ }^{32,99}$ Indeed, the level of nutrition knowledge today is relatively high, but many people do not know how to apply it nor are they motivated to change. ${ }^{100}$

Individuals generally underestimate their usual dietary intakes, although not always intentionally, ${ }^{101}$ and the underestimation tends to be greater among obese people. ${ }^{102-104}$ Consumers are also likely to have substantial misconceptions regarding the amounts of fat and energy in many common foods and in their overall diets. ${ }^{105-107}$ In one study, a majority of consumers in the United Kingdom reported that they had reduced their fat intakes, despite the fact that fat intakes as a percentage of energy had remained stable for the past 20 years. ${ }^{108}$ Likewise, another study showed that among meal planners who claimed to be on a special "low-fat/lowcholesterol diet, two-thirds of them consumed more that $30 \%$ of calories from total fat, and over half consumed more than $10 \%$ of calories from saturated fat. ${ }^{108}$ In a USDA focus group study, low-income participants expressed uncertainty about how the need to eat low-fat, high-fiber foods might translate into specific food choices. ${ }^{110}$ The report concluded that "a tension was apparent between what they believe they 'should' do (as revealed in their expressed intention to purchase more nutritious foods) and their food preferences and actual food choices." Thus, with respect to dietary change toward healthful diets, providing knowledge does not necessarily have much overall impact on behavior. 


\section{influences of Dietary Change}

\section{Models of Behavior Change}

Many social science theories are used to explain behavior change, a fact that alone emphasizes the complexity surrounding the food choice process. The principal theories and behavior techniques include the knowledge/attitude model; ${ }^{110}$ diffusion-of-innovations theory; ${ }^{111}$ health belief model; ;12 social cognitive theory; $;^{113}$ theory of reasoned action; ${ }^{114}$ and the stages-of-change theory. ${ }^{115-117}$ In addition, relapse prevention models are used to examine the maintenance of changed behaviors. ${ }^{118}$ Despite the fact that one single model is often used in dietary interventions, a combination of selected models appears to offer the most promise. ${ }^{119,120}$ At present, no one existing theory or model sufficiently explains and predicts the full range of foodchoice behaviors.

Long-term maintenance of dietary regimens typically varies from $20 \%$ to $80 \%,{ }^{121}$ with high relapse rates, ${ }^{122}$ and weight regain within 3 to 5 years after weight loss treatment. ${ }^{123}$ Nevertheless, small percentages of people do successfully change their diets and maintain the change over time. What is it about these particular groups of individuals that predicted their success? A closer look at the factors that facilitate or impede dietary change provides some insight into the complex web of social, behavioral, and environmental factors that affect the adoption and maintenance of more healthful diets.

Individual characteristics. Careful study of "health conscious" individuals who report a constellation of healthful behaviors and a lower risk of chronic disease demonstrates that consumption of a low-fat diet is higher among women, ${ }^{98,124,126}$ Caucasians, ${ }^{98}$ older adults,,${ }^{98,125,127}$ individuals living above the poverty level, those with more education, ${ }^{124,127}$ patients with a history of conditions related to heart disease, ${ }^{125}$ physically active individuals, ${ }^{128}$ and dietary supplement users. ${ }^{24,129,130}$ Women's motives for preventive dietary behavior vary with life stage, perceptions of body image, health status, and social roles. ${ }^{131}$ Certain dietary behaviors start early in life, as reported in one study of elementary school children. ${ }^{132} \mathrm{~A}$ greater selection of low-fat foods was observed in girls and was associated with grade level, maternal education level, and a household member with an elevated cholesterol level. In men, manual work and low occupational prestige have been linked to higher-than-average fat consumption. ${ }^{125}$

Barriers. Healthful, low-fat diets are not usually viewed as easy, attractive, or pleasant alternatives to current diets. Several studies have focused on the difficulties subjects anticipate will occur if they try to modify their diets, and what is actually encountered during those efforts. For the most part, anticipated problems are quite similar to actual barriers and include worries about taste, expense, giving up favorite foods, and lack of willpower.
Of particular concern in younger and higher educated individuals are difficulties with shopping and preparation. ${ }^{21,22,108,133,135}$

Social situations and those situations where a large quantity of food is present cause particular difficulties with diet modification. . $^{17,19,21,133}$ Interestingly, lack of social support was not anticipated as a barrier, but during focusgroup discussions was recognized as a key determinant of whether or not a family might consider making dietary changes. ${ }^{21}$

For patients with cardiac disease, counseling has been shown to increase adherence to dietary change. Factors that prevent patients from receiving counseling include cost, lack of interest, lack of time, lack of support, and lack of understanding of the benefits of counseling. ${ }^{136}$ In the Diet Alternatives for Lipid Lowering Study, the five most commonly cited barriers to following a low-fat diet were intentional decision, craving or urge to eat, availability of high-fat foods, poor planning, and having no appropriate foods available. ${ }^{19}$ In addition, studies have shown that different types of diets (e.g., low sodium, weight loss, low fat) may be associated with different types of barriers. ${ }^{137}$

Cultural preferences for high-fat meat products and other traditional foods may serve as a barrier for switching to low-fat foods. ${ }^{138}$ Such preferences have been substantiated by participants in a USDA focus-group study who indicated that "meat is essential for dinner" and that "it implies success and status."

Adherence to diets can be expected to decline when barriers are encountered. These include change in lifestyle, decreased taste, feelings of deprivation, concerns about increased costs (money, time, and convenience), and lack of reinforcement for participation. One prospective study found that three types of situations pose difficulties for dietary adherence: positive social situations where food cues were apparent, boredom, and negative affect. ${ }^{139}$ The main difference between a temptation (when an individual was tempted to go off the diet but did not) and an actual lapse was whether or not any coping responses were generated.

\section{Strategies for Fat Reduction}

\section{Theoretical Approaches}

Processes derived from the many models describing behavior change have been used to design intervention strategies and to identify stages of readiness to change. ${ }^{115,118,140}$ Recent studies on fat reduction have focused on the stages-of-change model: precontemplation, contemplation, preparation, action, and maintenance. ${ }^{141,144}$ Intervention strategies typically are targeted to the action and active maintenance stages, while social marketing and information dissemination are targeted to the earlier stages of contemplation and preparation. 
In the beginning of the change process-after people have identified their personal need to change--they must spend some time thinking before they take action (contemplation). Consciousness raising, self-evaluation, dramatic relief, and environmental reevaluation are all used to increase self-understanding, to assess personal feelings, to experience and express those feelings, and to assess how diet might affect their physical condition and the social environment. This contemplation period is often lengthy. When people are ready to initiate change, they make a commitment (self-liberation), seek social support (helping relationships), make specific food choices, and reinforce those choices (contingency management). The most difficult part of change is maintaining it. Action (continuation of the new food choice) alone is not enoughpeople need to review the need for the change (self-reevaluation and environmental reevaluation). People may need to remove themselves from situations that trigger old habits (counterconditioning and stimulus control). Finally, people who have changed can become advocates for the rights of others to do so (social liberation). This long list of processes indicates why change is difficult and why sustaining change is even more difficult.

Investigators have identified variables that distinguish self-changers from nonchangers, such as perception of personal susceptibility to diet-related diseases, perception of benefits from taking preventive health actions, overall health concerns, personal beliefs, cues to action, and locus of control. ${ }^{145}$ For example, nutrition intervention programs are more likely to be effective if recommendations for fat reduction strategies are made using "lay" categorizations. ${ }^{144}$

Thus, recommendations for changing food choices must do more than provide lists of foods to be eaten or avoided. The most fundamental steps in public health efforts to reduce fat in the diets of the general population are to emphasize actions that best serve individuals, thereby empowering people to make choices by giving them choices, and encouraging thinking as well as doing. ${ }^{146}$

\section{Specific Approaches}

Maintaining the palatability of the diet. As long as taste is a primary influence on food selection and dietary choice, ${ }^{41,42}$ strategies aimed at changing and improving diets must consider the sensory responses to foods. ${ }^{12}$ Because energy-dense foods and foods that combine sugar and fat are perceived as more palatable, ${ }^{75,147}$ efforts to persuade consumers to replace these foods with plant foods are unlikely to be sufficient. Palatability, the affective response to the taste, flavor, and texture of a food, adds to the pleasure of eating and cannot be ignored.

A few studies have shown that sustained consump- tion of low-fat diets leads people to develop a distaste for fat, thus encouraging continued adherence to a low-fat diet. ${ }^{127,148,149}$ There is little evidence to suggest, however, that the distaste is sustained. One study identified a decline in the hedonic response to fat in selected foods during 12 weeks on a low-fat diet when sensory exposure to fat was absent. ${ }^{150}$ No change in fat preference was seen when fat mimetics were part of the low-fat diet, suggesting that reduced preferences for fat may depend on reduced exposure to the properties of fat. In this situation, however, fat intake quickly returned to baseline levels during the 12-weeks of follow-up, and short-term changes in preference were not sufficient to produce long-term behavior change.

Behavioral strategies. Behavioral researchers have identified factors that are related to long-term adherence to treatment regimens. Some of these variables have been studied directly in the area of diet/exercise/weight control; others have been addressed in studies of medication adherence, but are clearly relevant to the area of diet change.

Self-monitoring. Continued self-monitoring of intake has been shown to be one of the strongest predictors of long-term weight loss. ${ }^{151}$ The few studies that have examined weight-loss maintenance consistently report that selfmonitoring of intake is related to long-term success. $\gtrless^{1,152}$ Individuals who have been successful at long-term weight control also continue to weigh themselves frequently. ${ }^{121}$ Better compliance with low-fat diets has been found in people who complete assigned food records. ${ }^{149}$ In a review of 30 published studies on dietary modification to reduce cardiovascular risk factors in adults, frequent dietary monitoring was reported to facilitate greater reductions in dietary fat intake..$^{20}$

Availability. Several studies done in community settings have shown that it is possible to change overall fat intake by changing the availability of foods and their costs without changing either fat preferences or knowledge. The availability of healthful products in grocery stores has been positively correlated with the reported healthfulness of individual diets. ${ }^{153,154}$ For example, in a large discount department store chain with 554 outlets in 34 states, a lowfat food program called "Good for You" was offered in the food service area. Increased sales of "Good for You" foods as a percentage of total sales were observed up to 9 months after initiation of the program. ${ }^{155}$ Consumption of fruits and vegetables was increased in a work-site cafeteria study by reducing prices $50 \%$ and increasing their availability; almost a threefold increase in salad and fruit purchasing was observed. ${ }^{156}$ Similarly, changing the price of low-fat items in vending machines almost doubled their selection (from $26 \%$ of purchases to $46 \%$ of purchases). ${ }^{157}$ Thus, reducing relative prices may be effective in promoting lower-fat food choices. 
Food provision. The importance of availability through the provision of food in influencing dietary adherence has been demonstrated in several clinical intervention trials..$^{20}$ One of the earliest such trials was the Diet Heart Study, in which participants who were able to purchase fat-modified products from a distribution center had $35 \%$ greater reductions in serum cholesterol than those given dietary advice alone.$^{158}$ Compliance with step 1 and step 2 NCEP/AHA recommendations was recently compared among subjects following a self-selected eating plan or a prepared meal plan in which prepackaged meals and snacks were delivered to their homes. Adherence to the diet and the clinical benefits were better among subjects given the prepackaged meals. ${ }^{159,160}$ In the Diet Alternatives for Lipid Lowering Study, ${ }^{19}$ men who kept situational logs indicated that easy access to appropriate foods was helpful, whereas availability of high-fat foods and unavailability of appropriate foods were barriers in adhering to a low-fat diet. Another study found that subjects who were provided meals achieved better weight losses than subjects given dietary advice without actual food provisjon. ${ }^{161}$ In an extension of this study, just giving participants specific meal plans and grocery lists was as effective as providing the food. ${ }^{162}$ Thus, with clear and specific instructions about what should be eaten, some people can make healthful food items more "available" to themselves.

Contingency contracts. Contingency contracts, in which participants are reinforced for weight loss and/or behavior change, have been shown to improve outcomes. ${ }^{163}$

Continued contact. Continued contact with treatment providers has been shown to improve long-term outcome. The best results appear to occur when contact is on a weekly or biweekly basis. ${ }^{164-166}$ In the area of diet change, it has been shown that more qualified and experienced treatment providers achieve better outcomes. ${ }^{167}$

Social support. Social support may influence health outcomes by encouraging individual behavior change. ${ }^{168}$ Previous studies have shown that involving a spouse in treatment programs improves outcome. ${ }^{158,166,169}$ However, the role of social support in the maintenance of dietary modification, fat reduction, and weight loss is not entirely clear because most studies fail to follow participants for longer than 1 year and to adequately assess the actual amount of support received. Several studies have reported positive associations between the amount of social support and long-term adherence to a low-fat diet, ${ }^{22,170}$ as well as better achievement of goals when social support is a factor. $^{21}$

Relapse prevention. Prevention of relapse is recognized as one of the greatest challenges in dietary-change programs. Increasing the awareness of high-risk situations that may cause people to lapse from their diet and providing strategies and skills for how to cope with such lapses have been shown to help reduce the risk that a lapse will lead to a relapse. ${ }^{118,119}$

Stimulus control. Studies on stimulus control have shown that modifying cues in the environment to increase cues for desired behaviors and to decrease cues for undesired behavicrs improves adherence. ${ }^{161}$

\section{Dietary Strategies}

Studies have shown that it is theoretically possible to achieve a reduced-fat diet $(<10 \%$ each from saturated and polyunsaturated fat and up to $15 \%$ monounsaturated) by introducing practical changes in eating patterns. This can be done without necessarily using special products, reducing the amounts of foods, or totally excluding commercially prepared foods. ${ }^{171}$ For example, women can achieve dietary recommendations by using skim milk and lean meats. ${ }^{126}$ Indeed, this pattern of dietary strategies is supported by the Women's Health Trial, which reported that reduced intake of three food groups-milk products, red meat, and fats/oils - accounted for almost $70 \%$ of the observed decrease in fat intake. ${ }^{172}$ "High level performers" (those who met their fat gram goals at 6, 12, and 24 months) were also compared with "low level performers" (those who met their fat gram goals only once, or not at all) at 24 months. The magnitude of change in the "high level performers" was most intense in terms of the reduction in the numbers of grams of fat.

A variety of specific food-choice strategies to reduce fat in the diet have also been demonstrated to be effective when reinforced. These include avoiding fat as a flavoring (such as on potatoes or bread), avoiding or reducing meat intake (either by partially or totally eliminating consumption or reducing portion sizes), modifying particular food choices (such as choosing tuna in water instead of tuna in oil), restricting certain types of foods, restricting quantities of foods (portion size), substituting similar foods for high-fat foods (using fat-modified salad dressings or lunch meats), and replacing higher-fat food choices with lower-fat ones (such as eating tofu instead of meat). ${ }^{173,174}$ Beef, hot dogs, and sweets are among the specific foods reduced or eliminated that discriminate between successful and unsuccessful weight losers/maintainers, ${ }^{175}$ as well as cheese, butter, high-fat snacks, and fried foods. ${ }^{176}$ Likewise, in the Women's Health Trial, successful women ate high-fat cheeses, bacon, hamburgers, whole milk, butter, mayonnaise, salad dressing, and potato chips less frequently; American and low-fat cottage cheese, skim milk, diet mayonnaise, pretzels, bagels, and English muffins were consumed more frequently. ${ }^{172}$

By far the most common strategy used by consumers to reduce dietary fat is the consumption of low-fat milk. Nationally, the consumption of low-fat milk has been increasing dramatically while whole-milk consumption has been decreasing. Between 1975 and 1995, annual sales of 
low-fat milk more than doubled and skim milk more than tripled, while whole-milk sales dropped by $50 \% .{ }^{177}$ On any given day in 1994, 56\% of Americans consumed milk; $19.3 \%$ consumed whole milk compared to $36.7 \%$ who consumed low-fat or skim. ${ }^{3}$ Interestingly, although low-fat milk is the most frequently mentioned fat-modified product in consumer surveys, it did not actually meet the FDA's Nutrition Labeling and Education Act criteria for the low-fat descriptor until recently.

The diets of people who regularly use strategies such as consuming skim milk, lean meats, or fat-modified products contain less fat, fewer calories, and higher levels of most vitamins and minerals than the diets of people who do not use these strategies., ${ }^{3,179}$

In theory, fat-modified foods that taste good can also help individuals comply with low-calorie diets; ${ }^{: 27,180}$ consuming them could be an easily adopted and maintained strategy for following a low-fat diet.,173,181 Fat-modified products can be used either as a substitute for the full-fat versions or as additions to the traditional diet. If a reduced-fat product (or a combination of products) substitutes for its higher-fat counterpart in similar amounts, a reduction in total fat, saturated fat, and energy would be expected. However, if such additions are accompanied by an overall protein or carbohydrate intake, caloric intake will increase.

\section{Healthy Lifestyle and Physical Activity}

A number of studies have reported an inverse association between physical activity and dietary fat intake in both men and women. Data from the Behavioral Risk Factor Surveillance System showed that inactive men consumed $37.1 \%$ of their calories as fat versus $30.2 \%$ for men who exercised regularly and intensely. ${ }^{128}$ Similarly, inactive women consumed $30.3 \%$ of their calories as fat versus $24.6 \%$ in women who were active regularly and intensely. Other studies comparing marathon runners or team athletes with the general population both support ${ }^{182,183}$ and oppose this finding. ${ }^{184}$

These findings differ from those obtained in randomized trials of exercise. In such studies, exercise seems to have little effect on dietary fat intake, although increases in carbohydrates are sometimes observed. ${ }^{185,186}$ Thus, these studies may indicate that people who choose to be more active may also choose a healthier eating plan, whereas increased exercise may not automatically influence diet choice.

Increased physical activity, however, is the variable most consistently related to long-term maintenance of weight loss. ${ }^{121,150}$ This variable emerges in both randomized controlled studies of long-term weight loss and in cross-sectional studies comparing more and less successful weight losers. ${ }^{187}$ The National Weight Control Registry recently published the dietary and activity strategies used by over 750 successful weight losers. ${ }^{120}$ To be eligible, participants must have lost at least 30 pounds and kept it off at least 1 year. On average, however, registry participants have lost approximately 60 pounds and kept it off 5 years. Analyses based on the first 700 subjects in the registry indicate that physical activity was a key component of their weight maintenance. These individuals reported expending an average of more than $2500 \mathrm{kcal} /$ week on physical activity, with approximately $25 \%$ from heavy (high-intensity) activities.

\section{Gaps in Research}

\section{Behavioral and Social Influences on Food Choice}

Research studies are needed to:

- Further identify the cultural factors that shape food choices.

- More completely identify the effects of education, income, and ethnicity on food behavior.

- Understand how life cycle stage affects dietary choices from childhood to adolescence to adulthood.

- Determine how infants' early experiences with high-fat breast milk or formula influence preferences for the flavor of high-fat foods.

- Determine environmental modifications that might influence dietary fat intake.

- Determine the cost effectiveness of increasing knowledge of healthful diets versus modifying the food and/ or eating environment.

- Determine how changes in fat intake produced by changing the environmental availability or cost of specific foods influence changes in fat preference over time.

- Determine how food preferences are necessary for food acceptance.

- Determine whether it is necessary to change food preferences in order to change food intake, or whether changing food intake changes food preference or both occur together.

- Determine how changes in fat intake are associated with changes in fat preferences.

- Determine how long periods of low-fat intake affect hedonic ratings and lead to unwavering changes in fat preference.

- Identify factors that affect consumer responses to food advertising.

- Identify methods for creating effective advertising for fruits, vegetables, and other nonprocessed foods.

- Identify and specify policies and educational methods to counter food advertising to children.

- Identify how consumers respond to low-fat dietary messages.

- Identify effective methods to promote healthful diets among the public. 
- Identify the social dynamics that encourage or suppress the concerns about dietary fat.

- Determine whether children's responsiveness to the energy density of foods predisposes them to prefer energy-dense foods and to reject reduced-fat, reducedenergy foods.

\section{Influences on Dietary Change}

Research studies are needed to:

- Determine the impact of culture on behavior change.

- Develop strategies that will produce long-term changes in dietary fat intake.

- Develop an understanding of what food and food choice really mean to consumers.

- Determine the coping strategies needed to maintain changed food-choice behaviors.

- Determine the dietary modification strategies that work most effectively with different types of people.

- Develop validated evaluation tools that will accurately measure food choice, dietary intake, and behavior change.

- Identify methods for shifting clustered behaviors from nonhealthy to healthy. Determine whether longer exposures to low-fat diets cause changes in hedonic ratings, reductions in caloric intakes, and increases in physical activity.

- Determine actual barriers - as opposed to anticipated barriers - to healthful diets.

- Determine the effects of rewards and incentives for positive behaviors versus punishment and disincentives for negative behaviors.

- Identify the long-term effects on food choices of weight loss studies.

- Compare difficulties in adhering to low-fat diets versus other types of regimens.

- Identify federal agriculture, assistance, and educational policies that can promote healthy dietary behaviors.

- Determine whether reduced-fat diets can serve as an important strategy in the primary prevention of obesity.

- Determine the effects of partnerships and collaborations on the effectiveness of dietary messages in inducing behavior change.

\section{Conclusion}

A more extensive understanding of barriers and strategies may help to produce food choices that lead to low-fat diets. Encouragement of long-term consumption of lowfat diets is important, since following such diets for even short periods of time may produce positive results such as: 1) decreased total calorie intake, ${ }^{149} 2$ ) reduced body weight, ${ }^{124,188,189,190}$ 3) improved lipid profiles, ${ }^{191,192}$ and 4) improved perceptions of dietary palatability. ${ }^{148}$

1. Symes SL. Strategy for health promotion. Prev Med 1986;15:492-507
2. Glanz K. Nutrition education for risk factor reduction and patient education: a review. Prev Med 1986;15:721-52

3. Sigman-Grant M. Can you have your low-fat cake and eat it too? The role of fat-modified products. J Am Diet Assoc 1997;97:S76-S81

4. Daily dietary fat and total food-energy intakesthird National Health Nutrition Examination Survey, Phase I, 1988-91. MMWR 1994;43:116-23

5. The Surgeon General's Report on Physical Activity and Health. Washington DC. U.S. Surgeon General; 1996

6. Flegal K. NHANES III: Trends in body weight and overweight in the U.S. population. Nutr Rev 1996;54:S97-100

7. Sobal J, Revicki D, DeForge B. Patterns of interrelationships among health promotion behaviors. Am J Prev Med 1992;8:351-9

8. Popkin B. The nutrition transition in low-income countries: an emerging crisis. Nutr Rev 1994;52:285-98

9. Chevassus-Agnes $\mathrm{S}$. Disponsilities des lipides alimentaires dans le monde. Food Nutr Agric 1994;11:15-22

10. Drewnowski A. Taste preferences and food intake. Ann Rev Nutr 1997;237-53

11. Drewnowski A. Energy intake and sensory properties of food. Am J Clin Nutr 1995;62:S1081-S1085

12. Perisse J, Sizaret F, Francois P. The effect of income and the structure of the diet. FOA Nutr News $1969 ; 7: 1-9$

13. Groth E. Communication with consumers about food safety and risk issues. Food Technol $1991 ; 248-53$

14. Mclntosh WA. Food and nutrition as social problems. In: Sociologies of Food and Nutrition. New York NY. Plenum Press;1996:215-34

15. Sobal J, Maurer D. Eating Agendas: Food and Nutrition as Social Problems. New York NY. Aldine DeGruyter;1995:ix-xiv

16. Sims L. The Politics of Fat. New York, NY. ME Sharpe; 1998

17. De Castro J. The relationship of cognitive restraint to the spontaneous food and fluid intake of freeliving humans. Physiol Behav 1995;57:287-95

18. Epstein L, Wing R, Koeske R, et al. Long-term effects of family-based treatment of childhood obesity. J Consult Clin Psych 1987;42:S91-S95

19. McCann B, Ratzlaff B, Walden C, et al. Dietary intervention for coronary heart disease prevention. In: The Handbook of Health Prevention Change. Shumaker ES, ed. New York NY. Springer Publishing; 1990

20. Barnard N, Akhtar A, Nicholson A. Factors that facilitate compliance to lower fat intake. Arch Fam Med 1995;4:153-8

21. Peterson S, Kris-Etherton PM, Sigman-Grant M. Perceived barriers to family implementation of a low-fat diet. J Home Econ 1994;6:5-12

22. American Dietetic Association. Nutrition trends survey. Chicago IL. American Dietetic Association;1997

23. Levy A, Schucker R. Patterns of nutrient intake among dietary supplement users: attitudinal and behavioral correlations. I Am Diet Assoc 
$1987 ; 87: 754-60$

24. Levy A, Strokes R. Effects of a health promotion advertising campaign on sales of ready-to-eat cereals. Public Health Rep 1987;102:398-403

25. Smith K. Alar: One year later. A media analysis of a hypothetical health risk. New York, NY. American Council on Health and Science; 1990

26. Foerster S. California dietary practices survey: focus on fruits and vegetables, trends among adult 1989-1995. Sacramento CA. California Department of Health Services; 1997

27. Gallo A. The food marketing system in 1994. Washington DC; USDA Agricultural Information Bulletin \#717;1995

28. Novelli W. Applying social marketing to health promotion and disease prevention. In: Health behavior and health education: theory, research, and practice. K Glanz, F Lewis, B Rimer, eds. San Francisco CA. Jossey-Bass;1990

29. Elitzak $\mathrm{H}$. Food marketing costs rose less than the farm value in 1995. Food Rev 1996;19:6-10

30. Gallo AE. The food marketing system in 1995. Washington DC. USDA Agricultural Information Bulletin \#731;1996

31. Sun T. Dramatic growth in mass media food advertising in the 1980s. Food Rev 1993;16:36-40

32. Institute of Medicine. Improving America's Diet and Health. Washington DC. National Academy Press; 1991

33. Blisard W, Blaylock J. Generic promotion of agricultural products. Washington DC. USDA Agricultural Information Bulletin;1989

34. Pierce J. Does tobacco advertising target young people to stop smoking? Evidence from California. JAMA 1991;266:3154-3158

35. Grube J. Television beer advertising and drinking knowledge, beliefs, and intentions among schoolaged children. Am J Publ Health 1994;84:254-9

36. Clancy K, Helitzer D. Food advertising. In: Weininger J, Briggs GM, eds. Nutrition Update. New York: John Wiley \& Sons 1983;1:357-9

37. National Science Foundation. Research on the effects of television advertising on children. Washington DC. Government Printing Office; 1977

38. Vanden Heede F, Pelican S. Reflections on marketing as an inappopriate model for nutrition education. J Nutr Educ 1995;27:141-5

39. Job R. Effective and ineffective use of fear in health promotion campaigns. Am J Publ Health 1988;78: 163-7

40. Shannon B, Rowan M. Threat versus benefit appeals for motivating adults to participate in a weightcontrol class. J Am Diet Assoc 1987;87:1381-83

41. Food Marketing Institute. Trends in the United States: Consumer attitudes and the supermarket. Washington DC;1997

42. Belzer H. The NPD Group's 11th annual report on eating patterns in America, National Eating Trends Tracking. The NPD Group, Port Washington NY. 1997

43. Food Marketing Institute. Shopping for health, 1997. Washington DC. FMI and Prevention Magazine;1997:1-39

44. Wechsler H, Basch C, Zybert P, et al. The Availability of low-fat milk in an inner city Latino community: implications for nutrition education. Am J Publ Health 1995;85:1690-92

45. Food Service Industry Fact Book. Washington DC; National Restaurant Association; 1993

46. Restaurant spending. Washington DC; National Restaurant Association; 1995

47. Senauer B, Asp E, Kinsey J. Food trends and the changing consumer. St Paul MN. Eagan Press; 1991

48. Smiciklas-Wright $\mathrm{H}$, Krebs-Smith S, Krebs-Smith J. Variety in foods. In: What is America eating? Washington DC. National Academy Press; 1986:126-40

49. Kant A, Schatzkin A, Block G. Food group intake patterns and associated nutrient profiles of the US population. J Am Diet Assoc 1991;91:1532-7

50. Drewnoswki A, Henderson SA, Driscoll A, et al. The dietary variety score: assessing diet quality in healthy young and older adults. J Am Diet Assoc 1997;97:266-71

51. Kant A, Schatzkin A, Harris T. Dietary diversity and subsequent mortakllity in the first national health and nutrition examination survey epidemiological follow-up study. Am J Clin Nutr 1993;57:434-40

52. Rolls B. Experimental analysis of the effects of variety in a meal on human feeding. Am $\mathrm{J}$ Clin Nutr 1985;45:932-9

53. Krebs-Smith S, Smiciklas-Wright $H$, Guthrie $H$, et al. The effects of variety in food choices on dietary quality. J Am Diet Assoc 1987;87:897-903

54. Kant A, Block G, Shatzkin A, et al. Association of fruit and vegetable intake with dietary fat intake. Nutr Res 1992;12:1441-54

55. Moskowitz H, Arabie P. Taste intensity as a function of stimulus concentration and solvent viscosity. J Text Stud 1970;1:502-10

56. Civille G, Liska I. Modificiations and applications to foods of the General Foods sensory texture profile technique. J Text Stud 1975;6:19-31

57. Drewnowski A. Dietary fats: perceptions and preferences. J Am Coll Nutr 1990;9:431-5

58. Halaas J, Gajiwala K, Maffei M, et al. Weight-reducing effects of the plasma protein encoded by the obese gene. Science 1995;269:543-6

59. Roberts $\mathrm{S}$, Greenberg A. The new obesity genes. Nutr Rev 1996;54:41-9

60. Leibowitz S, Kim T. Inpact of a galanin antagonist on exogenous and natural patterns of fat ingestion. Brain Res 1992;599:148-52

61. Drewnowski A, Krahn D, Demitrack M, et al. Naloxone, an opiate blocker, reduces the consumption of sweet high-fat foods in obese and lean female binge eaters. Am J Clin Nutr 1995;61:1206-12

62. Drewnowski A. Sweetness and obesity. In: Sweetness. Dobbing J, ed. Berlin, Germany Springer; 1986.

63. Drewnowski A, Brunzell J, Sandle K, et al. Sweet tooth reconsideration: taste responsiveness in human society. Physiol Behav 1985;35:617-22

64. Mela D, Sacchetti D. Sensory preferences for fats: relationships with diet and body composition. Am J Clin Nutr 1991;53:908-15

65. Fisher JO, Birch LL. Fat preferences and fat consumption of 3- to 5-year old children are related to parental adiposity. J Am Diet Assoc 1995;95:759 64 
66. Johnson SL, McPhee L, Birch LL. Conditioned preferences: young children prefer flavors associated with high dietary fat. Physiol Behav 1991;50:124551

67. Stubbs R. Macronutrient effects on appetite. Int $\mathrm{J}$ Obesity 1995;19:\$11-S19

68. Blundell J, Burley V, Cotton J, et al. Dietary fat and appetite control: weak effects on satiation (withinmeals) and satiety (following meals). In: Determinants of preference, selection, and consumption of dietary fats. Mela D, ed. London UK. Elsevier;1992

69. Drewnowski A, Kurth C, Holden-Wiltse J, et al. Food preferences in human obesity: carbohydrates versus fats. Appetite 1992;18:207-21

70. Drewnowski A. Metabolic determinants of binge eating. Addict Behav 1995;20:733-45

71. Popkin B, Paeratakul S, Zhai F, et al. Dietary and environmental correlates of obesity in a population study in China. Obesity Res 1995;3:135S-143S

72. Food Balance Sheets 1961-94. Rome Italy, Food and Agricultural Organization;1994

73. Gilbertson TA, Fontenot DT, Liu L, Zhang H, Monroe WT. Fatty acid modulation of $\mathrm{K}+$ channels in taste receptor cells: gustatory cues for dietary fat. Am J Physiol 1997;272:C1203-C1210

74. Cooper $H$. Texture in dairy products and its sensory evaluation. In: Food Texture: Instrumental and Sensory Measurement. Moskowitz HR, ed. New York NY. Marcel Dekker 1987;1:251-72

75. Drewnowski A. Fats and food texture: sensory and hedonic evaluations. In: Food Texture: Instrumental and Sensory Measurement. Moskowitz HR, ed. New York NY. Marcel Dekker 1987;1:267-83

76. Szczesniak A. Consumer awareness of texture and other food attributes II. J Text Studies 1971;2:196206

77. Steiner J. Facial expressions of the neonate infant indicating the hedonics of food-related chemical stimuli. In: The Genesis of Sweet Preferences. Weiffenbach JM, ed. Washington DC. USHEW DHEW Publ No 77-1068

78. Birch LL, Fisher JO. Food intake regulation in children. Annals NY Acad Sci 1997;819:194-220

79. Drewnowski A, Shrager EE, Lipsky C, et al. Sugar and fat: sensory and hedonic evaluatin of liquid and solid foods. Physiol Behav 1989;45:177-83

80. Bellisle F, Monneuse MO, Steptoe A, Wardle J. Weight concerns and eating patterns: a survey of university students in Europe. Int $\mathrm{J}$ Obesity Rel Metab Disor 1995;19:723-30

81. Birch LL. Children's preferences for high-fat foods. Nutr Rev 1992;50:249-55

82. Birch LL, Johnson SL, Fisher JA. Children's eating: the development of food-acceptance patterns. Young Children 1995;50:71-8

83. Drewnoswki A. Taste responsiveness in eating disorders. Ann NY Acad Sci 1989;575:399-409

84. Drewnoswki A, Halmi K, Pierce B, et al. Taste and eating disorders. Am J Clin Nutr 1987;46:442-50

85. Drewnowski A, Holden-Wiltse J. Taste responses and food preferences in obese women: effects on weight cycling. Int J Obesity 1992;16:639-48

86. Fomon S. Voluntary food intake and its regulation. In: Infant Nutrition. Philadelphia PA. WB Saunders;1974
87. Cowart B. Development of taste perception in humans: sensitivity and preference throughout the life span. Psychol Bull 1981;90:43-73

88. Mennella D, Beauchamp G. Maternal diet alters the sensory qualities of human milk and body composition. Pediatrics 1991;88:737-44

89. Birch LL, Fisher JA. The role of experience in the development of children's eating behavior. In: Why we eat: the psychology of eating. Capaldi, ED, ed. Washington DC. American Psychological Association;1996:113-41

90. Rozin P, Volimecke T. Food likes and dislikes. Ann Rev Nutr 1986;6:433-56

91. Rozin P, Kalat J. Specific hungers and poison avoidance as adaptive specializations of learning. Psychol Rev 1971;77:406-18

92. Sullivan S, Birch L. Pass the sugar, pass the salt; experience dictates preference. Dev Psychol 1990;26:546-51

93. Sclafani A. Nutritionally based learned flavor preferences in rates. In: Taste, experience, and feeding. Powley ECT, ed. Washington DC. American Psychological Association 1990;139-56

94. Fomon S. Nutrition of normal infants. St Louis MO. Mosby-Yearbook;1993

95. Gazzaniga J, Burns T. Relationship between diet composition and body fatness, with adjustment for resting expenditure and physical activity in preadolescent children. Am J Clin Nutr 1995;58:21-8

96. Nguyen V, Larson D, Johnson R, Goran M., Fat in- , take and adiposity in children of lean and obese parents. Am J Clin Nutr 1996;63:507-13

97. Peterson S, Sigman-Grant M. Impact of adopting lower-fat food choices on nutrient intake of American children. Pediatrics 1997;100:1-10

98. Munoz K, Krebs-Smith S. Food intakes of U.S. children and adolescents compared with recommendations. Pediatrics 1997;100:323-9

99. Baranowski T. The knowledge-attitudes-behavior model and defining "behavior changes". Charting the course for evaluation: how do we measure the success of nutrition education and promotion in food assistance programs. Arlington VA. USDA Food and Consumer Service;1995

100. Frazao E. The American diet: health and economic consequences. Washington DC. USDA Economic Research Service Agricul Info Bull No 711;1995

101. Mertz W. What are people really eating? The relation between energy intake derived from estimated diet records and intake determined to maintain body weight. Am J Clin Nutr 1991;54:291

102. Black A. Measurements of total energy expenditure provide insights into the validity of dietary measurements of energy intake. J Am Diet Assoc 1993;93:572

103. Lichtamm S. Discrepancy between self-reported and actual caloric intake and exercise in obese subjects. NEJM 1992;327:1893

104. Heitmann B, Lissner L. Dietary underreporting by obese individuals-is it specific or nonspecific? BMJ 1995;311:986-9

105. Mela D. Consumer estimates of the percentage energy from fat in common foods. Eur J Clin Nutr 1993;47:735-40

106. Levy AS, Fein SB, Stephenson M. Nutrition knowl- 
edge levels about dietary fats and cholesterol. $J$ Nutr Educ 1993;25:60-66

107. Frazao B, Cleveland L. Diet-health awareness about fat and cholesterol-only a start. Food Rev 1994;17:15-22

108. Lloyd HM, Paisley CM, Mela DJ. Barriers to the adoption of reduced-fat diets in a UK population. $J$ Am Diet Assoc 1995;95:316-22

109. Buss D. Food patterns in the British Isles. Ann Nutr Metab 1991;35:S12-S21

110. Dietary Guidelines Focus Group Final Report. Washington DC, USDA;1995

111. Rogers E. Diffusion of Innovations. New York NY. The Free Press; 1983

112. Becker M. The Health Belief Model and Personal Health Behavior. Thorofare NJ. Stock Publishing; 1974

113. Bandura A. Self efficacy: toward a unifying theory of behavior change. Psychol Rev 1977;84:191

114. Ajzen $I$, Fishbein $M$. Understanding attitudes and predicting social behavior. Englewood NJ. PrenticeHall;1980

115. Prochaska J, DiClemente C. Transtheoretical therapy: toward a more integrative model of change. Psychother Theory Res Pract 1982;19:458

116. Stafleu A, DeGraff C, Van Steveren W, et al. A review of selected studies assessing social psychological determinants of fat and cholesterol intake. Food Qual Pref 1991;92:183-200

117. Glanz K, Lewis F, Rimer B. Health behavior and health education: Theory, research, and practice. San Francisco CA. Jossey Bass; 1997

118. Marlatt G, Gordon J. Relapse prevention: maintenance strategies in addictive behavior change. New York NY: Guilford;1985

119. Brownell KD, Cohen LR. Adherence to dietary regimens 2: Components of effective interventions. Behav Med 1995;20:155-64

120. Contento I. The effectiveness of nutrition education and implications for nutrition education, policy, programs, and research: a review of research. J Nutr Educ 1995;27:277-418

121. Klem $M$, Wing $R$, McGuire $M$, et al. A descriptive study of individuals successful at long-term maintenance of substantial weight loss. Am J Clin Nutr 1997;66:239-246

122. Foreyt J, Goodrick G, Gotto A. Limitations of behavioral treatments of obesity. Review and analysis. J Behav Med 1981;4:150-74

123. Brownell KD, Jeffrey $R$. Improving long-term weight loss; pushing the limits of treatment. Behav Ther $1987 ; 18: 353-74$

124. Shepherd R, Stockley L. Nutrition knowledge, attitudes, and fat consumption. J Am Diet Assoc 1987;87:615-9

125. Baghurst K, Baghurst $P$, Record $S$. Demographic and dietary profiles of high and low-fat consumers in Australia. J Epidemiol Comm Health 1994;48:2632

126. Peterson S, Sigman-Grant M, Achterberg C. Lower fat food choices identified through a novel sorting procedure for CSFII 1989-91 data. Family Econ Nutr Rev 1997;10:36-48

127. Urban N, White E, Anderson GL. Correlates of main- tenance of a low-fat diet among women in the Women's Health Trial. Prev Med 1992;21:279-91

128. Simones E, Byers T, Coates R, et al. The association between leisure-time physical activity and dietary fat in American adults. Am J Publ Health 1985;85:240-44

129. Slesinski $M$, Subar $A$, Kahle $L$. Dietary intake of fat, fiber, and other nutrients is related to the use of vitamin and mineral supplements in the United States: the 1992 National Health Interview Survey. $J$ Nutr 1996;126:3001-8

130. Block G, Cox C, Madans J, et al. Vitamin supplement use, by demographic characteristics. Am J Epidemiol 1988;127:297-309

131. Devine CM, Olson CM. Women's dietary prevention motives: life stage influences. J Nutr Educ 1991;23:267-74

132. Whitaker R, Wright J, Koepsell T, et al. Characteristics of children selecting low-fat foods in an elementary school lunch program. Arch Pediatr Adolesc Med 1994;148:1085-91

133. Koikkalamen $M$. Why cardiac patients do not follow the nutritionist's advice: barriers to nutritional advice perceived in rehabilitation. Disab Rehab 1996;18:619-23

134. Frazo E, Allshouse J. Size and growth of the nutritionally improved foods market. Washington DC. USDA Agricultural Information Bureau;1996

135. Lappalainen R. Difficulties in trying to eat healthier: descriptive analysis of perceived barriers for healthy eating. Eur J Clin Nutr 1997;51:S36-S40

136. Hyman D, Clark M, Houston-Miller N, et al. Cholesterol-related counseling by regisered dietitians in Northern California. Prev Med 1992;21:746-53

137. Jeffery R, French $S$, Schmid T. Attributions for dietary failures: problems reported by participants in the hypertension prevention trial. Health Psychol 1990;9:315-29

138. Bardbard S, Michaels I, Fleming K, Campbell M. Understanding the food choices of low-income families: summary of findings. Washington DC, USDA and TAS; 1997

139. Grilo C, Shiffman S, Wing R. Relapse crises and coping among dieters. J Consult Clin Psychol 1989;57:488-95

140. Ni Mhurchu C, Margetts B, Speller V. Applying the stages-of-change model to dietary change. Nutr Rev 1997;55:10-16

141. Curry SJ, Kristal AR, Bowen DJ. An application of the stage model of behavior change to dietary fat reduction. Health Ed Res 1992;7:97-105

142. Greene GW, Rossi SR, Reed GR, et al. Stages of change for reducing dietary fat to $30 \%$ of energy or less. J Am Diet Assoc 1994;94:1105-10

143. Sporny LA, Contento IR. Stages of change in dietary fat reduction: social psychological correlates. J Nutr Educ 1995;27:191-99

144. Keenan DP, Achterberg C, Kris-Etherton PM, et al. Use of qualitative and quantitative methods to define behavioral fat-reduction strategies and their relationship to dietary fat reduction in the Patterns of Dietary Change Study. J Am Diet Assoc 1996;96:1245-50

145. Contento IR, Murphy BM. Psycho-social factors differentiating people who reported making desirable 
changes in their diets from those who did not. $J$ Nutr Educ 1990;22:6-14

146. Sullivan $\mathrm{LW}$. Steps toward a fat-free future. J Am Diet Assoc 1997;97:S52-S53

147. Drewnowski A, Greenwood M. Cream and sugar: human preferences for high-fat foods. Physiol Behav 1983;30:629-33

148. Hammer R. Calorie-restricted low-fat diet and exercise in obese women. Am J Clin Nutr 1989;49:77-85

149. Jeffery RW, Hellerstedt WL, French SA, et al. A randomized trial of counseling for fat restriction versus calorie restriction in the treatment of obesity. Int $\mathrm{J}$ Obesity Rel Metab Dis 1995;19:132-7

150. Mattes RRD. Fat preference and adherence to a reduced-fat diet. Am J Clin Nutr 1993;57:373-81

151. Guare J, Wing $R$, Marcus $M$, et al. Analysis of changes in eating behavior and weight loss in Type II diabetic patients. Diab Care 1989;12:500-3

152. Wadden TB, Letizia K. Predictors of attrition and weight loss in patients treated by moderate and severe caloric restriction. In: Treatment of the seriously obese patient. Wadden TB, Van Itallie TB, eds. New York NY. Guilford Press;1992:383-410

153. Cheadle A, Psaty B, Curry S, et al. Communitylevel comparisons between the grocery store environment and individual dietary practices. Prev Med 1991;20:250-61

154. Cheadle A, Psaty B, Curry S, et al. Can measures of the grocery store environment be used to track community-level dietary change? Prev Med 1993;22:361-72

155. Eldridge AL, Snyder MP, Faus NG, et al. Development and evaluation of a labeling program for lowfat foods in a discount department store foodservice area. J Nutr Educ 1997;29:159-61

156. Jeffery RW, French SA, Raether $C$, et al. An environmental intervention to increase fruit and salad purchases in a cafeteria. Prev Med 1994;23:78892

157. French SA, Jeffery RW, Story $M$, et al. A pricing strategy to promote low-fat snack choices through vending machines. Am J Publ Health 1997;87:849 51

158. National Diet-Heart Study Final Report. Circulation 1968;37\&38:1-428

159. Metz J, Kris-Etherton P, Morris C, et al. Dietary compliance and cardiovascular risk reduction with a prepared meal plan compared to a self-selected diet. Am J Clin Nutr 1997;66:373-85

160. McCarron DD, Oparil S, Chait A, et al. Nutritional management of cardiovascular risk factors: a randomized clinical trial. Arch Int Med 1997;157:16977

161. Jeffery $R$, Wing $R$, Thorson $C$, et al. Strengthening behavioral interventions for weight loss: a randomized trial of food provision and monetary incentives. J Consult Clin Psych 1993;61:1038-45

162. Wing $R$. Food provision vs structured meal plans in the behavioral treatment of obesity. Int J Obesity 1996;20:56-62

163. Jeffery $R$, Thompson $P$, Wing R. Effects on weight reduction of strong monetary contracts for calorie restriction or weight loss. Behav Res Ther $1978 ; 16: 363-9$
164. Wrisley D, Rubenfire M. Ineffectiveness of standardized dietary counseling in hypercholesterolemic patients with coronary disease. I Cardiopulm Rehab 1988;8:226-30

165. Ornish D, Brown S, Scherwitz L. Can lifestyle changes reverse coronary heart disease? Lancet 1990;336:129-33

166. Perri M, Nezu A, Viegener B. Improving the longterm management of obesity. New York NY. John Wiley and Sons; 1992

167. Southard DR, Winett RA, Walberg-Rankin JL, et al. Increasing the effectiveness of the National Cholesterol Education Program: dietary and behavioral interventions for clinical settings. Ann Behav Med 1992;14:21-30

168. Cohen S. Psychological models of the role of social support in the etiology of physical disease. Heaith Psychol 1988;7:269-97

169. Black A. A meta-analytic evaluation of couples weight-loss programs. Health Psych 1990;9:33047

170. Bovbjerg V, McCann B, Brief D, et al. Spouse support and long-term ahderence to lipid-lowering diets. Am J Epidemiol 1995;141:451-60

171. Smith-Schneider L, Sigman-Grant M, Kris-Etherton P. Dietary fat reduction strategies. J Am Diet Assoc 1992;92:34-9

172. Gorbach SL, Morrill-LaBrode A, Woods MN, et al. Changes in food patterns during a low-fat dietary intervention in women. $J$ Am Diet Assoc 1990;90:802-9

173. Kristal AR, White E, Shattuck AL. Long-term maintenance of a low-fat diet: durability of fat-related dietary habits inthe Women's Health Trial. J Am Diet Assoc 1992;92:553-9

174. Kristal AR, Shattuck AL, Henry HJ. Patterns of dietary behavior associated with selecting diets low in fat: reliability and validity of a behavioral approach to dietary assessment. J Am Diet Assoc 1990;90:214-20

175. Harris J, French S, Jeffery R, et al. Dietary and physical activity correlates of long-term weight loss. Obesity Res 1994;2:307-13

176. Holden J, Darga L, Olson S, et al. Long-term followup of patients attending a combination very-low calorie diet and behavior therapy weight loss program. Int J Obesity 1992;16:605-13

177. Milk Facts. Washington DC. Milk Industry Foundation/International Dairy Foods Association;1995

178. Cleveland L, Goldman J, Borrud L. Data Tables: Results frm USDA's 1994 continuing survey of food intakes by individuals and 1994 diet and health knowledge survey. Riverdale MD. Agricultural Research Service;1996

179. Sigman-Grant M, Kris-Etherton P, Peterson S. Impact of specific fat reduction strategies on nutrient intake of American adults and children. FASEB $J$ 1996;10:A488

180. Bolton M, Cousins J, Pace P, et al. Use of olestra in a nutrition education program. J Nutr Recipe Meal Dev 1996;2:33

181. Posner B, Franz M, Quatromoni P. Secular trends in diet and risk factors for cardiovascular disease. J Am Diet Assoc 1995;95:171-9

182. Nieman D, Butier J, Pollet $L$, et al. Nutrient intake of 
marathon runners. J Am Diet Assoc 1990;90:155762

183. Heinemann L, Zerbes $H$. Physical activity, fitness, and diet: behavioral in the population compared with elite athletes in the GDR. Am J Clin Nutr 1989;49:1007-16

184. Wankel L, Sefton J. Physical activity and other lifestyle behaviors. In: Physical activity, fitness, and health: International proceedings and consensus statement. Second International Conference on Physical Activity, Fitness, and Health. Toronto Canada. Stephens and Associates; 1992

185. Keim N, Canty D, Barbieri T, et al. Effect of exercise and dietary restraint on energy intake of reducedobese women. Appetite 1996;26:55-70

186. Wood T, Terry R, Haskell W. Metabolism of substrates: diet, lipoprotein metabolism, and exercise. Fed Proc 1985;44:358-63

187. Pronk N, Wing R. Physical activity and long-term maintenance of weight loss. Obesity Res 1994;2:
188. Prewitt T. Changes in body weight, body composition, and energy intake in women fed high- and low-fat diets. Am J Clin Nutr 1991;54:304-310

189. Kendall A, Levitsky DA, Strupp BJ, et al. Weight loss on a low-fat diet: consequence of the imprecision of the control of food intake in humans. Am J Clin Nutr 1991;53:1124-29

190. Gatenby S, Aaron J, Morton G, et al. Nutritional implications of reduced-fat food use by free-living consumers. Appetite 1995;25:241-52

191. Lichtenstein A, Ausman L, Carrasco W, et al. Shortterm consumption of a low-fat diet beneficially affects plasma lipid concentrations only when accompanied by weight loss. Arterioscler Thromb 1994;14:1751-60

192. Schaefer E, Lichtenstein A, Lamon-Fava S, et al. Body weight and low-density lipoprotein cholesterol changes after consumption of a low-fat ad libitum diet. JAMA 1995;274:1450-55

\section{Discussion}

Wing: I think a key question we have to deal with as a group today and as researchers is the question of whether it is necessary to first change fat preferences to get people to eat a low-fat diet. Or do we have to develop fat-modified foods that people actually prefer? Or alternatively, if we could get people to comply and eat a low-fat diet for an extended period of time - 6 months, let's say-would they over time eventually change their preferences to match their behavior? Do you have to change preferences to get behavior change? Or can you change behavior so that the preferences follow it?

I think the key question in the area of availability is what industry, researchers, and the health care, public health, and nutrition communities can do to increase the availability-and the accessibility-of low-fat foods. I raise these issues because they may push us to talk about not only behavior change at the individual level, but also behavior change at the environmental level-the societal level. What can we do to increase accessibility to good foods and decrease accessibility to foods that we don't want people to eat?

The million dollar question for us all in the area of behavior change is what motivates people over the long term. How do we develop our eating messages and our eating behavior change programs to develop and sustain long-term motivation?

Nestle: Our committee was charged with answering the question "Why?" with respect to dietary choices. To answer this question, we were faced with a very large set of data. My personal difficulty with these data comes from our assignment to single out fat from all of the other factors involved in dietary behavior. Irv Rosenberg used the term "artificial" to describe this process. It is indeed artifi- cial, mainly because dietary recommendations are meant to be followed as a whole. It is not enough just to reduce fat intake; people also are supposed to follow all of the other dietary guidelines.

Healthful diets reduce the intake of fat, saturated fat, and cholesterol, and follow the rest of our government's dietary policy guidelines: eat a variety of foods both within and across food groups; choose a diet with plenty of fruits, vegetables, and grains; maintain body weight or improve body weight by balancing caloric intake with physical activity; choose a diet moderate in salt, moderate in sugar, and moderate in alcohol, if at all.

The point of these guidelines is that all of them are supposed to be followed at the same time. These guidelines advise us to follow a dietary pattern that is low in fat and high in fruits, vegetables, and grains, that maintains our body weight, and in which we don't consume too much salt, sugar, or alcohol. We cannot do one without the other and still meet the principles of healthful diets.

The Dietary Guidelines for Americans are rather confusing because they contain words like "plenty," "moderate," and "choose" when the meanings of these words are not precise. Dietary guidelines also confuse nutrients with foods - eat less fat, salt, and sugar, but eat more fruits and vegetables.

From my experience with the 1988 Surgeon's General Report on Nutrition and Health, I learned that guidelines cannot make direct statements about food sources of dietary fat. Messages about fat cannot be translated into messages about food without causing trouble. The message "Eat less fat" is a euphemism for reducing intake of foods that are the major sources of fat in the American diet-meat, dairy, and processed foods. 